Article

\title{
Econometric Analyses of Adoption and Household-Level Impacts of Improved Rice Varieties in the Uplands of Yunnan, China
}

\author{
Huaiyu Wang ${ }^{1,2}$, Sushil Pandey ${ }^{3}$ and Lu Feng ${ }^{4, *}$ \\ 1 School of Management and Economics, Beijing Institute of Technology, Beijing 100081, China; \\ hwang@bit.edu.cn \\ 2 Sustainable Development Research Institute for Economy and Society of Beijing, Beijing 100081, China \\ 3 Independent consultant, Manila 1110, Philippines; sushilpandey056@gmail.com \\ 4 College of Economics and Management, Yunnan Agricultural University, Kunming 650200, China \\ * Correspondence: fenglu1128@126.com
}

Received: 3 July 2020; Accepted: 18 August 2020; Published: 24 August 2020

check for updates

\begin{abstract}
Higher-yielding rice varieties adapted to the upland conditions of Yunnan were developed and disseminated during the late 1990s. Using cross-sectional farm-level data of 448 households collected from five prefectures in Southern Yunnan, this paper carries out an econometric analysis of the determinants of variations in the adoption of improved varieties among households and assesses the impact of adoption on rice income and total household income. The two major determinants of adoption were found to be the government programs for extension of improved upland rice varieties and for terracing of sloping fields. The presence of government programs for extension and for terracing contributed to increased adoption of improved varieties. Household-specific factors such as land and labor endowments were less important as these variables had a statistically insignificant impact on adoption. The adoption of improved rice varieties increased both rice income and the average household income. About half of the household income difference observed between the full adopters and non-adopters of improved rice varieties with comparable household characteristics can be attributed directly to the adoption. The results imply that increased investments in promoting improved rice varieties and terracing will generate additional income growth in the uplands of Yunnan.
\end{abstract}

Keywords: improved rice varieties; technology adoption; impact assessment; uplands; Southern Yunnan

\section{Introduction}

Technological change has been a major source of growth in agriculture. This is exemplified clearly by the green revolution in the production of rice which is the staple crop of Asia. The spread of improved rice varieties together with the use of irrigation and fertilizers heralded the era of a rapid production growth that has contributed to improved food security and income growth in Asia [1]. These impacts of the green revolution in the irrigated areas of Asia have been widely documented and analyzed [1-5].

The growth in the productivity of rice in the rainfed areas of Asia, especially in the mountainous uplands, has been much slower. Upland areas are generally remote, with agriculture being mainly subsistence-oriented. Due to poor access to markets, farmers tend to concentrate their resources on food production to meet the subsistence needs. The incidence of poverty and food insecurity is very high in these uplands that are inhabited mainly by ethnic minorities [6]. In Asia, these mountainous 
uplands are spread over the northern parts of Myanmar, Thailand, Laos, and Vietnam and in the south-western province of Yunnan in China.

Traditionally, rice was grown in these uplands in a swidden system. This method involves clearing the forest vegetation by burning and growing upland rice in cleared fields for two to three years before abandoning the field and moving to clear another field for growing upland rice. The rising population pressure and limited availability of forested areas for clearing have forced farmers to cultivate the same area more frequently leading to a reduction in the productivity of rice. This increasing intensification pressure on the marginal uplands has resulted in environmental degradation in the form of forest encroachment and soil erosion. The marginal uplands of Asia can be described as essentially caught in a vicious cycle of poverty, low productivity, food insecurity, and environmental degradation [7].

This description of rice systems in the uplands provides a general picture of problems associated with food production in remote uplands in many parts of Asia, including Yunnan which is a relatively poorer southwestern province of China. However, there have been some major positive developments in the uplands of Yunnan over the past couple of decades. The productivity of upland rice has increased rapidly from $1.3 \mathrm{t} / \mathrm{ha}$ in 1990 to around 4t/ha in 2005-2006 [8,9]. A major factor contributing to the growth in rice productivity in the uplands of Yunnan is the development of high-yielding upland rice varieties and their rapid spread. Farmers also adopted terracing which, together with improved varieties, contributed to the productivity growth of rice in these uplands [10-12]. The traditional swiddening, although still practiced in some areas, has been largely replaced by permanent cultivation. With improvements in their food security situation, farmers are increasingly diversifying agricultural activities for income generation. Improved productivity of upland rice has also reduced the intensification pressure on these fragile sloping uplands as food requirements have been met from smaller areas due to higher productivity. These changes are contributing to improved food security, income growth, and environmental protection in the uplands of Yunnan $[8,9]$. It appears that the improved rice technology (comprising of improved high-yielding rice varieties and terracing) has served as an important entry point for turning the vicious cycle mentioned above into a virtuous cycle of higher productivity, higher incomes, and improved environmental outcomes [13]. This experience in Yunnan is likely to have important lessons not only for Yunnan but also for upland development in neighboring countries in the region.

The main purpose of this paper is to analyze the factors determining the adoption of improved rice varieties in the uplands of Southern Yunnan and assess the impact of such adoption on household incomes. Despite the potential role of increased upland rice productivity in improving household food security and incomes, the patterns of adoption of improved technologies and the impact on farmers' incomes in Yunnan have not been studied adequately. Empirical information on the determinants of technology adoption and impact could be helpful in designing more effective strategies and programs for future upland development in Yunnan and beyond.

In an earlier study, the farm-level yield effects of the adoption of improved rice varieties and terraces but did not identify the factors determining the extent of adoption of these technologies [9]. In addition, the results were based on a simple comparison of average yields across farms "with" and "without" these improved technologies. The yield effects based on such simple comparisons are, however, likely to be biased upwards due to the "self-selection bias" as farmers who are better skilled are also more likely to adopt improved technologies. The further study corrected for such self-selection bias through the use of an econometric model but failed to assess the impact of improved varieties as distinct from that of the adoption of terraces [14]. The current paper overcomes the limitations of these past studies by using suitable econometric models that provide unbiased estimates of the impact of improved upland rice varieties on farmers' incomes while also identifying factors determining adoption.

The paper is organized as follows. The next section describes the development and dissemination of upland rice technologies in Yunnan. Methodology and data are presented in the third section. The production system based on upland rice and the characteristics of upland farmers are subsequently 
described. The main results and discussions are included in the fifth section. The final section includes some implications of the findings for the agricultural development of Yunnan and the neighboring regions.

\section{Development and Dissemination of Improved Upland Rice Varieties in Yunnan}

The Yunnan province is home to around 46 million people most of whom belong to ethnic minority groups. It is one of the poorest provinces in China, with the incidence of poverty being high, especially in the mountainous upland areas. From 2015 to 2019, the poverty ratio in Yunnan dropped from $14.03 \%$ to $1.32 \%$ [15], while the national poverty ratio dropped from $10.2 \%$ to $1.7 \%$ [16].The velocity of poverty alleviation was higher and showed great importance in national policies. However, Yunnan still accounts for $12 \%$ of the total number of poor people in the country.

The government of Yunnan has implemented several initiatives over time for the development of uplands. One such initiative has been the development and dissemination of improved upland rice varieties in areas where farmers depend heavily on the production of upland rice for food security. The government also promoted the construction of terraces to stabilize sloping agricultural areas and improve their productivity. In addition, various programs were implemented to expand the area under cash crops for income generation.

Yunnan Academy of Agricultural Sciences (YAAS) has been the key organization involved in the development of improved rice varieties suitable for upland conditions. Local traditional varieties and breeding lines from Africa (Oryza glaberrima) were used as parents to develop higher-yielding upland rice varieties [17-19]. Since the late 1990s, several improved upland rice varieties (such as IRAT104, Yunlu 29, B6144F-MR-6, and Yunlu 52) have been released by the Yunnan Academy of Agricultural Sciences (YAAS). These improved varieties have been disseminated widely through extension programs implemented by local government agencies. Adoption of improved rice varieties and the average yield of upland rice increased in Southern Yunnan over time as a result $[9,14,20]$.

\section{Methodology and Data}

The two technological interventions considered in this paper are the improved upland rice varieties and the terracing in sloping uplands. Factors determining variations in the adoption of these technologies are identified using an econometric model. The impact of these technologies on farm household incomes is similarly assessed econometrically. The required data are generated through a cross-sectional survey of farm households.

\subsection{Data Collection and Sampling Design}

This study was based on farm-household data collected from five prefectures of Southern Yunnan, namely Honghe, Lincang, Pu'er, Wenshan, and Xishuangbanna. Upland rice is widely grown in these prefectures. A sample survey of a total of 448 households with upland rice from 16 villages of these prefectures was conducted in 2005 (Table 1). Information on household characteristics, their resource endowments (land and labor), major crops grown, rice varieties, input use, crop production, and household incomes were collected during the survey which was implemented in two phases using structured pre-tested questionnaires. Key informant interviews and focus group discussions were also conducted to collect background information and the specifics of rice technologies prior to the implementation of the farm household survey. The farm-level data were collected by the lead author in collaboration with the staff of the Yunnan Academy of Agricultural Sciences (YAAS) and the local authorities. A stratified random sampling technique was used to select the households. The counties selected represented variations in geographic features (such as remoteness and the slope of upland fields) and local climatic features. A stratified random sampling technique was used to select the households $[9,14]$. Villages were first selected on the basis of proportionate area under upland rice, and households from those villages were selected randomly. 
Table 1. Sampling Scheme.

\begin{tabular}{|c|c|c|c|c|c|c|}
\hline Prefecture & County & $\begin{array}{l}\text { Rainfall } \\
(\mathrm{mm})\end{array}$ & Village & $\begin{array}{l}\text { Altitude } \\
\text { (meters) }\end{array}$ & $\begin{array}{c}\text { Distance to the } \\
\text { Nearest Market }(\mathrm{km})\end{array}$ & $\begin{array}{c}\text { No. of } \\
\text { Samples }\end{array}$ \\
\hline Honghe & Pingbian & 1650.2 & Cangfang & 1761 & 11 & 26 \\
\hline Lincang & Cangyuan & 1748.8 & Tuanjie & 1755 & 6 & 28 \\
\hline $\mathrm{Pu}^{\prime} \mathrm{er}$ & Lancang & 1643.4 & Fotang & 1814 & 5 & 18 \\
\hline- & - & - & Laomian & 1627 & 14 & 25 \\
\hline- & - & - & Xiaohuilong & 1385 & 3 & 36 \\
\hline- & - & - & Xiyun & 1389 & 7 & 33 \\
\hline- & Menglian & 1373.2 & Bansong & 1145 & 12 & 34 \\
\hline- & - & - & Guangsan & 1004 & 3 & 31 \\
\hline- & - & - & Hani & 1455 & 3 & 30 \\
\hline - & - & - & Laomianzhai & 1277 & 13 & 33 \\
\hline- & - & - & Mangnuo & 1027 & 8 & 23 \\
\hline Wenshan & Wenshan & 999.8 & Duobaiku & 1810 & 9 & 34 \\
\hline Xishuangbanna & Jinghong & 1211.1 & Xinzhai & 845.4 & 9 & 31 \\
\hline- & Menghai & 1933.1 & Laodong & 1491 & 40 & 20 \\
\hline - & - & - & Zhongzhai & 1563 & 26 & 22 \\
\hline- & Mengla & 1550.8 & Panshan & 755.7 & 10 & 24 \\
\hline Total & - & - & - & - & - & 448 \\
\hline
\end{tabular}

Note: The rainfall data is the data in 2002 and collected from the statistic yearbook at the county level. The nearest market refers to the market where farmers trade their products.

\subsection{Econometric Modeling of Adoption Patterns and Impact}

Two sets of econometric models were used: one for analyzing the adoption of improved rice varieties and the other for estimating the impact of adoption.

\section{Adoption model}

The extent of adoption, measured here as percentage area under improved upland rice varieties, is a continuous variable that is limited between zero and 100 percent. A Tobit specification is appropriate for analyzing models with such limited dependent variables and has been used widely in adoption studies [21].

The Tobit model, originally developed by Tobin (1958), is specified as:

$$
\begin{aligned}
Y_{i}= & X_{i} \beta+\varepsilon_{i} \text { if } X_{i} \beta+\varepsilon_{i}>0 \\
= & 0 \text { if } X_{i} \beta+\varepsilon_{i} \leq 0(\mathrm{I}) \\
& \text { and } \varepsilon_{i} \sim N\left(0, \sigma^{2}\right)
\end{aligned}
$$

where $Y_{i}$ is the proportion of rice area under improved varieties, $X_{i}$ is a vector of variables capturing the farm and household characteristics, $\beta$ is a vector of unknown coefficients, and $\varepsilon$ is an error term that is assumed to be independently distributed with mean zero and a constant variance. The coefficients $\beta \mathrm{s}$ can be used to measure the marginal effect of each of the exogenous variables on the extent of adoption. In adoption studies, exogenous variables specified typically include household characteristics, farm characteristics, and external factors such as prices, climatic conditions, and institutional factors [22-25].

In this study, the household-specific factors included were the endowments of land and labor and the share of terraced upland area in the total upland rice area. The theory of induced innovation predicts that the relative proportion of land and labor endowments of a household determines the relative desirability of adoption of land-intensive or labor-intensive technologies [26]. A farm household with less land relative to family labor is more likely to adopt yield-increasing technologies than otherwise, ceteris paribus. This variation in land/labor endowment among households could be a factor partially explaining the variation in the extent of the adoption of yield-increasing improved upland rice varieties.

Terracing of upland fields encourages the adoption of improved rice varieties. Terraced fields retain water and fertilizers better than sloping fields, resulting in higher productivity. The effect of terracing on the adoption of improved varieties is hence expected to be positive. 
Adoption decisions are critically influenced by the presence/absence of technology extension programs. The presence of an active extension program to promote improved technology in a village is expected to have a positive impact on adoption. The government of Yunnan has made extensive efforts to promote improved upland rice varieties, but some villages are covered better than others while some villages are not covered at all. Thus, this variation in the extension coverage could be a factor explaining the observed variation in adoption.

The estimating equation for the Tobit model is specified in this study as:

$$
Y_{i}=\alpha_{i}+\beta_{1 i} X_{1 i}+\beta_{2 i} X_{2 i}+\beta_{3 i} X_{3 i}+\beta_{4 i} X_{4 i}+\varepsilon_{i}
$$

where, $Y_{i}$ is the proportionate area under improved upland rice variety for the $\mathrm{i}$-th household, $X_{1 i}$ is the ratio of land/labor endowment for the $i$-th household, $X_{2 i}$ is share of terrace area in upland area for the $i$-th household, $X_{3}$ is the dummy for the extension program, $X_{4}$ represents the county dummy (with value 1 for Menglian county, 0 otherwise), and $\varepsilon$ is the random error term.

The estimating equation is specified in a "reduced form" rather than in a "structural form" as the interest in the paper is in estimating the ultimate impact of exogenous variables on adoption. The use of the reduced form also avoids the potential problems of endogeneity that need to be considered in a structural model. In addition, the explanatory variables included are clearly exogenous in the cross-sectional data that reflect the household choices on rice varieties conditional on household resource endowments and the presence/absence of government programs on terracing/extension.

Impact model. Various econometric approaches exist for assessing the impact of an intervention [27]. Of these, the propensity score matching method (PSM) has been a popular approach to estimate the treatment effects in diverse research fields in situations where the counterfactual is not observable [28]. Self-selection by households into a program can lead to a bias in the estimation of treatment effects when the counter-factual is not observable as it is not possible to keep other factors constant while comparing the treatment effects in the more standard "with" and "without" framework. The PSM technique is now widely used to correct for potential self-selection biases in assessing the impact [28]. The PSM uses a non-parametric estimation method [29,30] and reduces the dimension for matching between adopters and non-adopters that are similar in terms of their observable characteristics [28,31].

The propensity score is defined as the conditional probability of receiving a treatment given pretreatment characteristics [32]:

$$
p(X)=\operatorname{Pr}(T=1 \mid X)=E(T \mid X)
$$

where $p(\mathrm{X})$ denotes the propensity score under $\mathrm{X}$, the multidimensional vector of pretreatment characteristics, $\mathrm{T}$ is the indicator of exposure to treatment, and $\operatorname{Pr}(\mathrm{T}=1 \mid \mathrm{X})$ is the conditional probability which equals to the expectation with respect to the distribution of $X$.

Given $Y_{1}$ and $Y_{2}$ as the outcome "with" and "without" improved variety adoption, the average treatment effects on the treated group can be estimated as follows:

$$
A T T=\mathrm{E}\left(Y_{1}-Y_{0} \mid T=1\right)=\mathrm{E}\left(Y_{1} \mid T=1\right)-\mathrm{E}\left(Y_{0} \mid T=1\right)=\frac{1}{n} \sum_{i=1}^{n}\left(y_{i, t=1}-y_{i, t=0}\right)
$$

The required propensity scores were estimated by a logit model which is specified as follows:

$$
\operatorname{logit}(p)=\ln [p /(1-p)]=\beta_{0}+\beta_{1} x_{1}+\beta_{2} x_{2}+\beta_{3} x_{3}+\beta_{4} x_{4}+\varepsilon
$$

where $p$ is the probability of farmers' technology adoption. In the propensity score matching method (PSM), only the variables that influence simultaneously the participation decision and the outcome variable but are unaffected by participation (or the anticipation of it) should be included. 
The explanatory variables include the ratio of land/labor endowment $\left(x_{1}\right)$, share of terrace area in the upland area $\left(x_{2}\right)$, extension program dummy $\left(x_{3}\right)$, and county dummy $\left(x_{4}\right)$. $\beta$ s are the coefficients to be estimated.

The nearest neighbor matching method was implemented to estimate the average impact and the radius and kernel matching methods as alternative specifications for assessing the sensitivity of results with respect to matching methods. These matching methods are widely used to assess the sensitivity of results with respect to the alternative specification of counterfactual [28]. The software STATA was used for estimation.

\subsection{Data Sets Used}

The data collected from 448 households were used for analysis. This large sample exhibited a considerable variation in the extent of adoption among households, including zero and $100 \%$ adoption of improved varieties. This variation in data provided an opportunity to model the adoption behavior and impact in some focused way for a sharper contrast.

The survey data captured large cross-sectional variations in rice production environments across locations spread over eight counties and altitude levels as well as wide responses in adoption patterns. Unexplained variations in the analysis of pooled cross-sectional data are bound to be high in such a data set. Given this, it was decided that a more efficient approach would be to use a sub-set of data for a sharper contrast in response variables. Accordingly, a truncated data set that included only partial adopters (defined as those households who adopted improved rice varieties in a part of the farm only) was used to conduct econometric analyses of factors determining the variations in the adoption rate among households. This smaller subsample of 114 partial adopters still contained considerable variations in adoption rates to permit a broader generalization of findings.

For estimating the impact of adoption, a different data strategy was used. A sharper contrast on impact can be expected if the comparison is made between non-adopters and full adopters. Thus, the data for 197 non-adopters and 137 full adopters were used for this purpose. For impact evaluation, farmers' total household income and rice income were considered as the two relevant indicators of impact.

\section{Results and Discussions}

\subsection{Characteristics of Adoption and Adopters}

Overall, the average area under improved upland varieties is $34 \%$ of the total upland rice area (Table 2). Therefore, almost $2 / 3$ of the upland rice area has remained under traditional varieties. The proportion of farmers adopting improved varieties is $56 \%$, which is higher than the proportion of area under improved varieties, indicating that many farmers grow improved varieties in only a part of their upland rice area. It can take many years for upland farmers to accept the introduced varieties, especially the poor upland farmers in remote areas, due to the uncertainties and risks [9]. Thus, they typically grow improved varieties initially in a small area and expand this area over time as they become more confident about the suitability of the new varieties in their fields. The use of a new variety may be discontinued if farmers find it to be unsuitable. This experimenting and learning process is an important part of the adoption of any new technology [22].

There are considerable variations in the adoption of improved upland rice varieties across the survey locations. The adoption rate is almost $100 \%$ in Jinghong County but some locations also have zero adoption (Fotang in Lancang County, Zhongzhai in Menghai County, and Panshan in Mengla County). Similarly, the difference between the proportion of households adopting improved varieties and the proportion of area under improved varieties is different across locations, indicating considerable variability in adoption patterns. Agroclimatic conditions, household resource endowments, market access, and the level of economic development vary across these locations and these factors jointly determine the adoption rate of improved upland rice varieties. 
Table 2. Adoption rate of improved varieties (IVs)

\begin{tabular}{cccc}
\hline County & Village & $\begin{array}{c}\text { Percentage of Households } \\
\text { Adopting IV (\%) }\end{array}$ & $\begin{array}{c}\text { Percentage of IV Area } \\
\text { to Upland Rice Area (\%) }\end{array}$ \\
\hline Pingbian & Cangfang & 50 & 44 \\
Cangyuan & Tuanjie & 15 & 13 \\
Lancang & Fotang & 0 & 0 \\
- & Laomian & 91 & 16 \\
- & Xiaohuilong & 27 & 12 \\
- & Xiyun & 38 & 27 \\
Menglian & Bansong & 76 & 43 \\
- & Guangsan & 97 & 58 \\
- & Hani & 100 & 82 \\
- & Laomianzhai & 94 & 35 \\
- & Mangnuo & 87 & 74 \\
Wenshan & Duobaiku & 59 & 53 \\
Jinghong & Xinzhai & 97 & 97 \\
Menghai & Laodong & 76 & 71 \\
- & Zhongzhai & 0 & 0 \\
Mengla & Panshan & 0 & 0 \\
\hline Total & - & 56 & 34 \\
\hline
\end{tabular}

Source: Wang et al. (2010).

Adoption of improved varieties may be of three types: full adoption, partial adoption, or zero adoption. Farmers who grow new varieties in all of their land are considered full adopters while those who grow new varieties in only a part of their land are partial adopters. Those who do not adopt at all and continue the traditional varieties are non-adopters. Of the total sample of 448 households, $44 \%$ of the households did not adopt improved rice varieties and grew traditional varieties only (Table 3). Among those who adopted improved varieties, $45 \%$ were partial adopters while the remaining $55 \%$ were full adopters. The average adoption rate (proportion of upland area under improved varieties) among partial adopters is $38 \%$.

Variations in technology adoption across households are typically explained by a combination of household-specific and farm-specific factors. Household specific factors include endowments of land and labor, farmer skills, and financial capacity. Farm-specific factors include land characteristics (e.g., soil type, slope, and soil fertility). A simple comparison of these factors across three categories of farmers is made to discern the key factors determining adoption (Table 3).

The household endowment of labor is broadly similar across household groups belonging to the three categories of adoption. However, the average farm size and the upland area of full adopters are smaller than those of the other two categories (Table 3). The average yield of upland rice of full adopters is $33 \%$ and $23 \%$ higher than those of non-adopters and partial adopters. For partial adopters, this is the weighted average yield of improved and traditional varieties, with weights being the respective proportion of area under each variety type. In terms of the total household income, full adopters have about $35 \%$ higher income than the other two categories. This total income includes the value of rice produced and the cash income obtained from the production of cash crops, livestock, and employment in non-farm activities.

The observed difference in the average income between full adopters and non-adopters of improved rice varieties consists of the direct effect of adoption through yield increases, the indirect effect of adoption through any reallocation of household resources from rice to production of cash crops that may have resulted from the adoption of improved varieties and the effect of differences in initial resource endowments of these two groups of farmers. The data, however, do not permit disaggregation of this total effect into individual components. 
Table 3. Characteristics of non-adopters, partial, and full adopters of improved technology

\begin{tabular}{|c|c|c|c|c|}
\hline & Non-adopters & Partial Adopters & Full Adopters & All \\
\hline Sample & 197 & 114 & 137 & 448 \\
\hline \multicolumn{5}{|l|}{ Human Capital } \\
\hline $\begin{array}{l}\text { Household size (number of family } \\
\text { members/hh) }\end{array}$ & 4.69 & 4.63 & 4.76 & 4.69 \\
\hline Labor (number of farm labor/hh) & 2.68 & 2.38 & 2.43 & 2.53 \\
\hline Rice area labor ratio (ha per farm labor) & 0.17 & 0.26 & 0.14 & 0.19 \\
\hline \multicolumn{5}{|l|}{ Physical Capital } \\
\hline Total land area (ha/hh) & 2.59 & 2.04 & 1.81 & 2.21 \\
\hline Upland area (ha/hh) & 1.73 & 1.67 & 1.19 & 1.55 \\
\hline Irrigated rice area (ha/hh) & 0.07 & 0.11 & 0.07 & 0.08 \\
\hline \multicolumn{5}{|l|}{ Upland Rice Production } \\
\hline Upland rice area (ha/hh) & 0.44 & 0.56 & 0.31 & 0.43 \\
\hline Share of upland rice area in upland area (\%) & 39 & 39 & 34 & 38 \\
\hline Share of IV area in upland rice area (\%) & 0 & 38 & 100 & 40 \\
\hline Yield of upland rice (t/ha) & 2.32 & 2.68 & 3.32 & 2.72 \\
\hline Upland rice production per household (ton) & 0.98 & 1.54 & 0.99 & 1.13 \\
\hline Household Cash Income (USD/hh) & 937 & 943 & 1276 & 1041 \\
\hline Sales of grains & 107 & 110 & 60 & 93 \\
\hline Sales of livestock & 227 & 196 & 229 & 220 \\
\hline Sales of cash crop & 419 & 453 & 819 & 549 \\
\hline Manual work & 64 & 33 & 91 & 64 \\
\hline Others & 120 & 151 & 77 & 116 \\
\hline Total Household Income (USD/hh) & 1204 & 1369 & 1546 & 1351 \\
\hline
\end{tabular}

Note: Total household income is defined here as the sum of cash income and the gross value of home-consumed agricultural products including rice. The exchange rate of $1 \mathrm{USD}=7$ Yuan is used.

\subsection{Returns to Improved Upland Rice Varieties}

The average farm-level yield of improved upland varieties is estimated to be $3.4 \mathrm{t} / \mathrm{ha}$ which is $30 \%$ higher than that of the traditional varieties (Table 4 ). This yield is close to the yields obtained in experiment trials [8]. Input use, especially fertilizers, is higher for improved varieties than for traditional varieties. Net returns (defined as the gross value of output minus the cash cost of production) of improved varieties is $31 \%$ higher than that of traditional varieties. Yield difference is the main driver of the difference in net returns as indicated by the similarity in the proportionate yield advantage of improved varieties and the proportionate gain in net returns over the traditional varieties.

Table 4. Yield, input use, and returns of upland rice production by variety.

\begin{tabular}{lcc}
\hline & Traditional Variety & Improved Variety \\
\hline Yield (t/ha) & 2.63 & 3.42 \\
Inputs & - & - \\
Seed (kg/ha) & 178 & 110 \\
Urea (kg/ha) & 152 & 217 \\
Superphosphate fertilizer (kg/ha) & 156 & 159 \\
Calcium magnesium phosphate & 247 & 323 \\
(kg/ha) & 13 & 35 \\
Compound fertilizer (kg/ha) & - & - \\
Returns & 564 & 733 \\
Value of output (USD/ha) & 154 & 194 \\
Value of input (USD/ha) & 37 & 47 \\
Seed input & 71 & 101 \\
Fertilizer & 40 & 40 \\
Herbicide & 6 & 6 \\
Pesticide & 410 & 539 \\
Net returns (USD/ha) & & \\
\hline
\end{tabular}

\subsection{Determinants of Adoption}

The results of Tobit estimation are presented in Table 5. The signs of the coefficients of explanatory variables are as expected. Terracing has a positive and significant effect on the extent of adoption 
with a 1 percentage-point increase in the terraced area being associated with a $0.4 \%$ increase in the proportionate area under improved varieties. In the sample, almost all terraced fields are grown to improved rice varieties.

Table 5. Tobit regression of the extent of adoption of improved upland rice variety.

\begin{tabular}{lcc}
\hline & Coefficients & $t$-Value \\
\hline Land labor ratio & -1.55 & -0.47 \\
Share of terrace area in land area (\%) & $0.37^{* * *}$ & 2.91 \\
Dummy for extension program & $12.91^{* *}$ & 2.53 \\
County dummy & $20.21^{* * *}$ & 4.26 \\
Constant & 8.48 & 1.32 \\
\hline \multicolumn{1}{c}{$\mathrm{N}$} & 113 & -
\end{tabular}

Note: Share of the improved upland rice variety area in rice area is taken as the dependent variable. ${ }^{* * *}, * *$, and * imply statistical significance at $1 \%, 5 \%$, and $10 \%$, respectively.

The presence/absence of an extension program for promoting improved upland rice varieties was another critical determinant of adoption. The positive coefficient associated with this variable indicates that the extent of adoption is higher in locations with active extension programs. The positive effect of an extension program on adoption is also widely reported in other adoption studies [33-35]. The variable land-labor ratio has the expected positive effect on adoption, but the coefficient was statistically not significant.

\subsection{Assessment of Impact}

Summary results of the impact estimate derived from the application of the PSM model are shown in Table 6. Two models were estimated, one for the income from rice only and the other for the total household income from all sources as the dependent variable. The covariates used in the model were a land-labor ratio, proportion of terraced area, presence/absence of a varietal extension program, and a county-level dummy. Depending on the matching algorithm used, the estimate of the difference in the average rice income per household between the adopter and non-adopter of improved rice variety was found to be in the range of USD $45-51$, accounting for $42-48 \%$ of non-adopters' cash income from grain sales. The rice income difference accounts for $50-62 \%$ of the total income effect. The balance of the income difference arises from non-rice sources. This balance could be partly due to the potential indirect effect of the adoption of improved varieties on changes in the area of cash crops and partly due to other unobserved differences not accounted for in the PSM model. The estimated average impact was found to be insensitive to alternative matching algorithms. The distribution of the propensity scores and the region of common support indicated sufficient overlap and balancing in the covariate distribution between the treated and control groups. To test the robustness of the model and potential unmeasured biases, we also calculated the Rosenbaum bounds. The results (not presented here) were indicative of robustness and the absence of systematic biases.

The results also indicate that the use of the more common but simple "with" and "without" comparison would have led to a substantial overestimation of the benefits attributable to the adoption of improved varieties. The use of the PSM method, which uses the propensity score for identifying households with similar characteristics for the comparison of treatment effects, seems to have improved the estimate of impact.

The results thus indicate that the direct impact of the adoption of rice varieties accounts for a major share of the total income effect of adoption. This is to be expected, but the indirect effect arising through changes in agricultural resource allocation from rice to other crops is also likely to be non-trivial. No quantitative estimates of this indirect effect can be derived from the survey data but farmer interviews indicated that many farmers who adopted improved varieties of rice expanded the 
area under cash crops as they were able to obtain adequate rice production for meeting the family needs from a smaller area.

The results are consistent with the previous studies that the adoption of improved upland rice varieties contributes to the household income positively $[9,14]$. With the higher yield achieved in upland rice production, farmers can have better rice income by selling the surplus grain after ensuring their food security. In addition, improvements in food security also facilitate agricultural diversification by releasing land and labor previously tied up in rice production.

Table 6. Impact of improved varieties on household income and rice income.

\begin{tabular}{lc}
\hline \multicolumn{1}{c}{ Matching Algorithm } & Average Effects (USD/household) \\
\hline Total household income & - \\
Nearest neighbor matching & 72 \\
Radius matching & 102 \\
Kernel-based matching & 86 \\
Rice income & - \\
Nearest neighbor matching & 48 \\
Radius matching & 45 \\
Kernel-based matching & 51 \\
\hline
\end{tabular}

Note: For these matching algorithms, the proportions of the number of units treated to the number of control units are all over $80 \%$.

\section{Concluding Remarks}

The results of this study clearly indicate that the two major factors determining the extent of the adoption of improved rice varieties in the uplands of Yunnan are government programs for extension and for terracing. These government-sponsored and subsidized programs launched in a centrally-directed manner are somewhat targeted to specific locations due to logistical and budgetary constraints. Household-level differences in resource endowments seem to matter less as indicated by the statistically insignificant coefficients of land/labor ratios. The presence/absence of government programs seems to be the main factor determining the extent of adoption. The implications for Yunnan are quite clear: more promotion programs are needed to facilitate greater spatial coverage across prefectures/counties where upland rice is widely grown.

As production environments vary across locations, new improved varieties adapted to those environments would also need to be developed further to increase the coverage of high-yielding varieties. Improved rice varieties that are drought tolerant are likely to be more suitable in the drought-prone uplands of Yunnan. Based on the mapping of drought-prone areas and an analysis of drought characteristics, additional resources may need to be invested in a scientific breeding program for developing drought-tolerant rice varieties adapted to uplands. Overall, a two-pronged strategy of developing rice varieties suited to key production environments and active promotion of such technologies is needed to increase the productivity of rice.

The results also indicate that the adoption of improved varieties generated substantial income effects among adopters. About half of the household income difference observed between full adopters and non-adopters of improved varieties with comparable household characteristics can be attributed directly to the adoption. The absolute size of the gain in household income, however, varies according to the rice area.

The overall implications of the results for upland development of Yunnan are that more investments are needed to develop and promote improved rice varieties throughout the uplands of Yunnan. The provision of such technologies could complement other interventions for upland development that will help farmers overcome food insecurity and engage in other income-generating activities like commercial crop production. This strategy could also be applicable in promoting upland development in the neighboring upland regions of Northern Vietnam, Northern Laos, and Northern Myanmar. 
Author Contributions: The main work of investigation, formal analysis and original draft writing were done by H.W. The conceptualization, methodology, draft writing and editing were contributed significantly by S.P., and L.F. contributed to the resources and validation. All authors have read and agreed to the published version of the manuscript.

Funding: This research was funded by the National Science Foundation of China [71403016 and 71403234], Beijing Social Science Foundation [19JDYJB020] and Special Fund for Joint Development Program of Beijing Municipal Commission of Education. And the APC was funded by Yunnan Provincial Talented Young Scientist Programme [2019HB032]. We are thankful for the anonymous reviewers' valuable comments and suggestions to improve the manuscript.

Conflicts of Interest: All three authors declare that they have no conflict of interest.

\section{References}

1. Hazell, P. Asia's Green Revolution: Past achievements and future challenges. In Rice in the Golbal Economy: Strategic Research and Policy Issues for Food Security; Pandey, S., Byerlee, D., Dawe, D., Dobermann, A., Monhanty, S., Rozelle, S., Hardy, B., Eds.; International Rice Research Institute: Los Banos, Philippines, 2010; pp. 61-92.

2. Hazell, P. An Assessment of the Impact of Agricultural Research in South Asia since the Green Revolution; CGIAR Science Councial Secretariat: Rome, Italy, 2008.

3. Evenson, R.E.; Gollin, D. Assessing the impact of the Green Revolution, 1960 to 2000. Science 2003, 300, 758-762. [CrossRef] [PubMed]

4. Kajisa, K.; Payongayong, E. Potential of and constraints to the rice Green Revolution in Mozambique: A case study of the Chokwe irrigation scheme. Food Policy 2011, 36, 614-625. [CrossRef]

5. Stone, G.D.; Glover, D. Disembedding grain: Golden Rice, the Green Revolution, and heirloom seeds in the Philippines. Agric. Hum. Values 2017, 34, 87-102. [CrossRef]

6. Pandey, S.; Khiem, N.T.; Waibel, H.; Thien, T.C. Upland Rice, Household Food Security, and Commercialization of Upland Agriculture in Vietnam; International Rice Research Institute: Los Banos, Philippines, 2006; p. 106.

7. Pandey, S. Food security, poverty and environmental sustainability in the uplands: The strategic role of rice research. In Natural Resource Management for Poverty Reduction and Environmental; Haefele, S.M., Ismail, A.M., Eds.; The World Bank: Washington, DC, USA, 2009.

8. Atlin, G.N.; Lafitte, H.R.; Tao, D.; Laza, A.; Amante, A.; Courtois, B. Developing rice cultivars for high-fertility upland systems in the Asian tropics. Field Crop. Res. 2006, 97, 43-52. [CrossRef]

9. Wang, H.; Pandey, S.; Hu, F.; Xu, P.; Zhou, J.; Li, J.; Deng, X.; Feng, L.; Wen, L.; Li, J.; et al. Farmers' Adoption of Improved Upland Rice Technologies for Sustainable Mountain Development in Southern Yunnan. Mt. Res. Dev. 2010, 30, 373-380. [CrossRef]

10. People's Daily Online. 2016-02-16. Yunnan has built 17.44 million mu (about 1.16 million ha) of high and stable farmland in 5 years. Available online: http://yn.people.com.cn/n2/2016/0216/c372442-27740823.html (accessed on 16 June 2020).

11. Xinhuanet. 2009-11-20. Yunnan will transform middle and low yield fields in mountainous areas vigorously. Available online: http://news.sohu.com/20091120/n268360212.shtml (accessed on 16 June 2020).

12. Yunnannet. 2019-07-19. Yunnan promotes 870,600 mu (about 58,040 ha) of new upland rice varieties. Available online: http://society.yunnan.cn/system/2019/07/19/030332587.shtml (accessed on 16 June 2020).

13. International Rice Research Institute (IRRI) and Ministry of Agriculture (MOA), People' Republic of China. Summary of the International Workshop on Strategies for Sustainable Development of Agriculture Production Systems in the Highlands of the Greater Mekong Subregion (GMS) Countries (unpublished); Kunming, China, 2003.

14. Wu, H.; Ding, S.; Pandey, S.; Tao, D. Assessing the Impact of Agricultural Technology Adoption on Farmers' Well-being Using Propensity-Score Matching Analysis in Rural China. Asian Econ. J. 2010, 24, 141-160. [CrossRef]

15. China News. Yunnan's poverty ratio dropped from $14.03 \%$ to $1.32 \%$. Available online: http://www.yn. chinanews.com/news/2020/0612/57455.html (accessed on 12 June 2020).

16. People's Network. The incidence of poverty in the country has dropped from $10.2 \%$ to $1.7 \%$ over the past 7 years. Available online: http://zj.people.com.cn/n2/2019/1018/c186327-33448790.html (accessed on 18 October 2019). 
17. Hu, F.; Tao, D.; Sacks, E.; Fu, B.Y.; Li, J.; Yang, Y.; McNally, K.; Khush, G.S.; Paterson, A.H.; Li, Z.K. Convergent evolution of perenniality in rice and sorghum. Proc. Natl. Acad. Sci. USA 2003, 100, 4050-4054. [CrossRef]

18. Tao, D.; Xu, P.; Yang, Y.; Hu, F.; Li, J.; Zhou, J. Studies on fertility in interspecific hybrids between Oryza sativa and O. glaberrima. Rice Genet. Newsl. 2003, 20, 71-73.

19. Tao, D.; Xu, P.; Li, J.; Hu, F.; Yang, Y.; Zhou, J.; Tan, X.; Jones, M. Inheritance and mapping of male sterility restoration gene in upland japonica restorer lines. Euphytica 2004, 138, 247-254. [CrossRef]

20. Chen, Y.P.; Wu, H.T.; Tao, D.; Sushil, P.; Xu, P.; Hu, F.; Ding, S.; Wang, H.; Feng, L. Assessing the Effects of Agricultural Technology Adoption on Farmers' Income Using Propensity Score Matching Method: Evidence from Upland Rice Farmers in Southwestern Yunnan. Sci. Agric. Sin. 2010, 43, 3667-3676.

21. Wooldridge, J.M. Econometric Analysis of Cross Section and Panel Data; MIT Press: Cambridge, MA, USA, 2002.

22. Feder, G.; Just, R.E.; Zilberman, D. Adoption of agricultural innovations in developing countries: A survey. Econ. Dev. Cult. Chang. 1985, 33, 255-298. [CrossRef]

23. Sunding, D.; Zilberman, D. The agricultural innovation process: Research and technology adoption in a changing agricultural sector. Handb. Agric. Econ. 2001, 18, 207-261.

24. Doss, C.R. Analyzing technology adoption using microstudies: Limitations, challenges, and opportunities for improvement. Agric. Econ. 2006, 34, 207-219. [CrossRef]

25. Foster, A.D.; Rosenzweig, M.R. Microeconomics of Technology Adoption; Economic Growth Center Discussion Paper Series No.984; Yale University: New Haven, CT, USA, 2010; Available online: http://www.econ.yale. edu/growth_pdf/cdp984.pdf (accessed on 16 June 2020).

26. Piesse, J.; Schimmelpfennig, D.; Thirtle, C. An error correction model of induced innovation in UK agriculture. Appl. Econ. 2011, 43, 4081-4094. [CrossRef]

27. Shahidur, R.K.; Koolwal, G.B.; Samad, A.H. Handbook on Impact Evaluation: Quantitative Methods and Practices; The World Bank: Washington, DC, USA, 2010.

28. Caliendo, M.; Kopeinig, S. Some practical guidance for the implementation of propensity score matching. J. Econ. Surv. 2008, 22, 31-72. [CrossRef]

29. Imbens, G.W. Nonparametric estimation of average treatment effects under exogeneity: A review. Rev. Econ. Stat. 2004, 86, 4-29. [CrossRef]

30. Abebaw, D.; Fentie, Y.; Kassa, B. The impact of a food security program on household food consumption in Northwestern Ethiopia: A matching estimator approach. Food Policy 2010, 35, 286-293. [CrossRef]

31. Dehejia, R.H.; Wahba, S. Propensity score-matching methods for nonexperimental causal studies. Rev. Econ. Stat. 2002, 84, 151-161. [CrossRef]

32. Rosenbaum, P.R.; Rubin, D.B. The central role of the propensity score in observational studies for causal effects. Biometrika 1983, 70, 41-55. [CrossRef]

33. Moser, C.M.; Barrett, C.B. The complex dynamics of smallholder technology adoption: The case of SRI in Madagascar. Agric. Econ. 2006, 35, 373-388. [CrossRef]

34. Johnson, M.E.; Masters, W.A.; Preckel, P.V. Diffusion and spillover of new technology: A heterogeneous-agent model for cassava in West Africa. Agric. Econ. 2006, 35, 119-129. [CrossRef]

35. Basu, A.K.; Qaim, M. On the adoption of genetically modified seeds in developing countries and the optimal types of government intervention. Am. J. Agric. Econ. 2007, 89, 784-804. [CrossRef]

(C) 2020 by the authors. Licensee MDPI, Basel, Switzerland. This article is an open access article distributed under the terms and conditions of the Creative Commons Attribution (CC BY) license (http://creativecommons.org/licenses/by/4.0/). 